\title{
Analysis of Water Temperature Influenced by Arduino-Controlled on Solar Desalinator of Low Cost
}

João Dehon da Rocha Junior ${ }^{1}$, Rafael Leandro Fernandes Melo ${ }^{1}$, João Felipe Vieira Lima ${ }^{2}$, Isabel Cristina da Cósta Souza ${ }^{3}$, Jose Josemar de Oliveira Junior ${ }^{4}$ and Luiz Guilherme Meira de Souza ${ }^{4}$

1. Departamento de Mecânica, Instituto Federal do Ceará, Tabuleiro do Norte, Ceará 62960-000, Brazil

2. Departamento de Engenharia Mecânica, Universidade Federal do Paraná, Curitiba 81530-000, Brazil

3. Departamento Bioquímica e Biologia Molecular, Universidade Federal do Ceará, Fortaleza 60020-181, Brazil

4. Departamento de Engenharia Mecânica, Universidade Federal do Rio Grande do Norte, Natal 59014-615, Brazil

\begin{abstract}
The solar desalinator is a low cost installation and operation equipment that can contribute to tackling the problem of water shortages in the world. Because of the importance of this equipment, the present work has the objective to quantify the relation of the temperature of the water with the production of the equipment. For this, a compact desalinator with glass cover in square pyramidal form and a heating system controlled by a logic programmer was built. As a result, it was verified the efficiency of the logic controller as an auxiliary tool for experimental work and the relationship between temperature ranges and desalination production.
\end{abstract}

Key words: Solar desalinator, temperature of water influence, logical programmer, solar energy, compact desalinator.

\section{Introduction}

According to Schiermeier [1], up to a fifth of the world's population can suffer serious shortages in water supply if the world's temperature is raised to $2{ }^{\circ} \mathrm{C}$. This real concern about the availability of drinking water to the world justifies the need for studies aimed at the purification of water unfit for consumption.

The purification of water, whether from the sea or polluted, is the solution to the prevention of global scarcity. There are several techniques for this purpose, one of which is the desalinator. Due to the abundance of solar energy, the desalinator that uses this energy is considered as green equipment.

In fact, one of the most promising energy alternatives for the world is the use of abundant and clean solar energy. It is an environmentally friendly

Corresponding author: Rafael Leandro Fernandes Melo, master of materials engineering, research field: computational modelling materials. energy source with unmatched potential with any other energy system. Because Brazil is a tropical country, solar energy availability is equivalent to 1.13 $\times 1,010 \mathrm{GWh}$ in most of the year. In order to have an idea of this potential, the annual amount of solar energy that the earth receives corresponds to 10,000 times the world energy consumption in this period [2].

The application of solar energy in desalination of water is a technique that allows the obtaining of drinking water in an ecologically correct way and with minimum production cost. This technique is so efficient and easy to apply that Shiva Gorijan [3] states that the problems of water scarcity in Iran can be solved by applying this desalination technique.

The solar desalinator consists basically of a reservoir of water (water to be treated) and a cover that allows the entrance of the solar radiation and prevents its exit (provoking the greenhouse effect) and allows the condensation and collection of the treated fluid [4].

The level of solar radiation, ambient temperature, wind speed, relative humidity, the presence of clouds 
and dust are natural parameters that directly influence the production of the solar desalinator [5]. The ambient temperature is directly related to the desalinator productivity, with the temperature variation from $20^{\circ} \mathrm{C}$ to $40{ }^{\circ} \mathrm{C}$, there is an increase of approximately $14 \%$ in the production of a simple solar desalinator, as well as increasing the productivity of a desaliner as a result of fluid preheating [6].

The evaluation of the influence of water temperature on the desalinator production is a study that allows a better understanding of the equipment and becomes the first step to verify the efficiency of the application of techniques that increase the temperature of the fluid to increase water production.

In this context, the objective of this paper is to present the manufacturing process of a compact solar desalinator of simple and easily constructed materials with four-sided pyramidal coverage and to verify the influence of temperature on its production. It also aims to show the performance of logical programmers in aid of practical studies.

\subsection{Solar Energy}

The main source of energy on planet earth is the sun. In the form of radiation, this energy can be both a source of heat and light. Solar radiation is a short-wave electromagnetic energy, only one part of it hits the earth, another is absorbed by the atmosphere. The intensity of the radiation varies with the time of year and with latitude [7].

The amount of daily solar radiation that the planet receives has such a high potential that it can supply the world's energy needs ten thousand times in that period. Brazil, despite the different types of existing climates, has an annual average of uniform solar radiation, with high averages. The values of solar radiation incident in any region of the country vary from 4.2 to $6.7 \mathrm{kWh} / \mathrm{m}^{2}$. Thus solar energy availability is equivalent to $1.13 \times 1,010 \mathrm{GWh}$ in most of the year [8].

Due to the high availability of energy and the cost to use it, solar energy is being increasingly demanded and, therefore, technologies for its use are being developed at all times.

The use of this source to obtain desalinated water is a method that has several advantages such as low initial investment, operation and maintenance costs.

\subsection{Solar Desalinator}

The solar desalinator consists of a black vessel filled with brackish or saline water up to a certain depth and covered by a slanted glass to facilitate the transmission of solar radiation and the condensation of the water vapor generated. The solar radiation that enters the equipment heats the black container which in turn heats the water causing its evaporation. Because of the pressure difference and temperature difference with the exterior, the water vapor rises and is condensed along the inclined glass lid and is collected by a suitable container in the lower part [9].

The productivity of the desalinator can be increased by the association of other devices to cause water heating, such as the association of a parabolic concentrator, collectors [10], concentrator mirrors [11], among others.

Cooper [12] found that the type of insulation of the tank walls, the thickness of the water slide and the inclination of the glass cover impacted the performance of the equipment. Deronzier [13] developed a multi-effect solar distiller with several coupled solar collectors and 12 stages of evaporation, which resulted in high production, reaching up to 35 liters per square meter day $\left(\mathrm{L} / \mathrm{m}^{2} /\right.$ day). Chendo [14] found that by filling the black vessel with rocks, the distiller increased production and allowed desalination for up to 4 hours after sunset.

\subsection{Logical Programming Aided by Arduino}

Free hardware platforms have become very important in teaching and engineering development in recent years. Among them is the arduino, characterized by its versatility, popularity and low price. The logic controller has a plethora of applications, including 
temperature control, which can be done simply and quickly [15].

The low cost, the ease and the amount of information open make the device to be applied in both education and industry. The device is nothing more than a free platform for programming.

The use of arduino for the production of scholarly works is something growing around the world. The present work used this platform to obtain the temperature control in narrow bands and to allow the greater reliability of the results.

\section{Experimental Apparatus}

Aiming at the best understanding of this article, the methodology was divided into three main topics: (1) construction of the solar desalinator, (2) construction of the temperature control system and (3) data collection and treatment.

\subsection{Construction of the Solar Desalinator}

The desalinator was constructed from a recipient to serve as a reservoir, lamella for the uptake of water, the glass to form the cover and the styrofoam to serve as thermal insulation. All the materials used for the construction of the desalinator are shown in Fig. 1.

A CAD design (computer assited design) was used to guide the construction (Fig. 2) and the design of the desalinator with its dimesões is shown in Fig. 3.

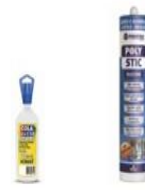

(a)(b)

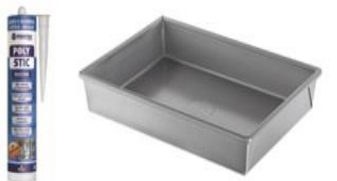

(c)

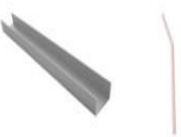

(d)

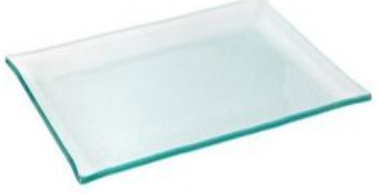

(f)

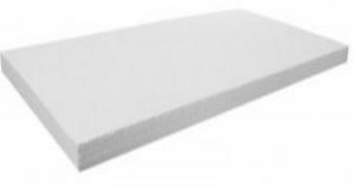

(g)
Fig. 1 Materials used for the construction of the furnace: (a) polystyrene glue; (b) industrial silicon; (c) aluminum container; (d) U-shaped aluminum lamella; (e) straw; (f) 3 mm glass sheet and (g) $40 \mathrm{~mm}$ styrofoam sheet.

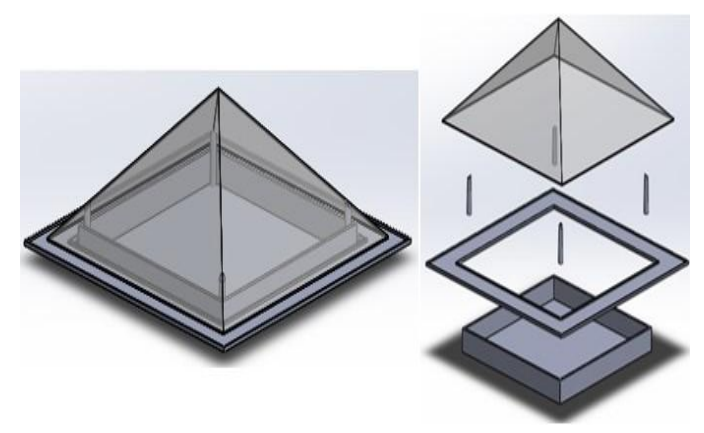

Fig. 2 Desalinator design.

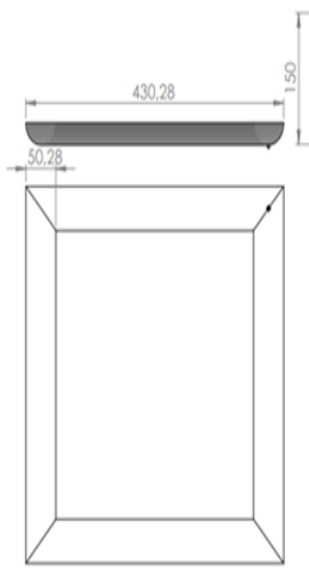

(a)

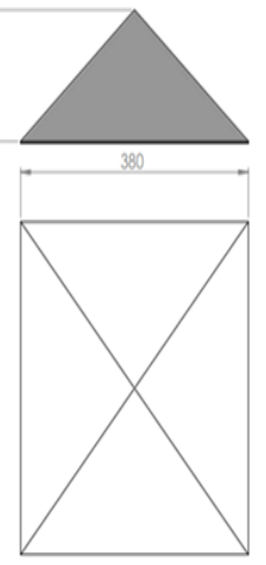

(b)

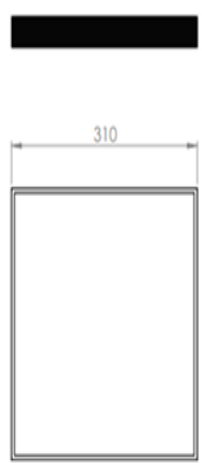

(c)
Fig. 3 Dimensions of the desalinator: (a) gutter; (b) glass cover and (c) the recipient.

With the design defined, the construction phase (physical) of the equipment was started.

The glass was cut into 4 triangles which were glued with silicone to obtain a 4-sided pyramidal geometry, an angle of $52^{\circ}$ was taken with the horizontal. Then, the lamella was cut and joined with the aid of the silicone and painted white to form a square gutter to collect the desalted water, its internal width was $2 \mathrm{~mm}$.

The nozzle to drain the fluid was created from a straw.

The recipient was painted black and had its connections sealed with silicone. Finally, the thermal insulation of the desalinator was made with polystyrene and polystyrene glue, so that the insulation thickness was $40 \mathrm{~mm}$. The final design is shown in Fig. 4.

\subsection{Construction of the Temperature Control System}

For the control of temperature were used: an Arduino 


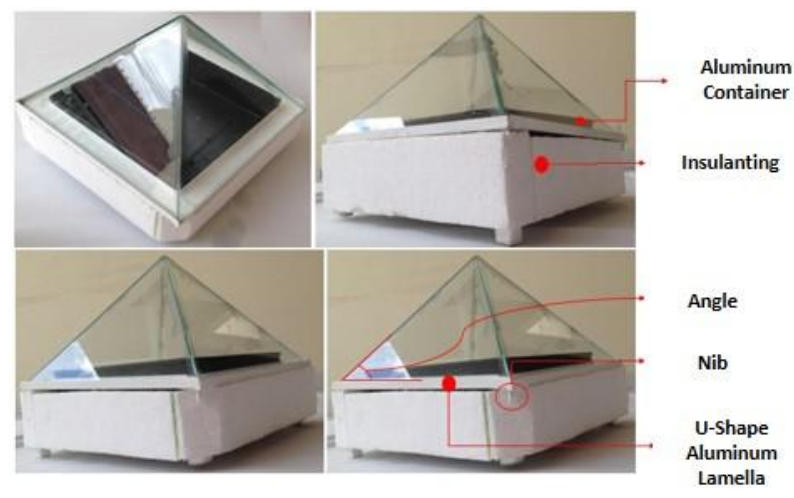

Fig. 4 Desalinator finalized.

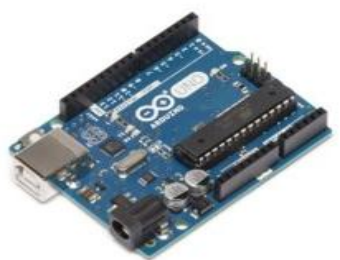

a)

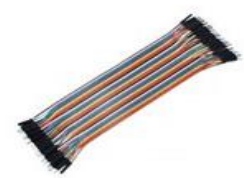

f)

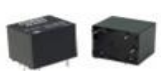

b)

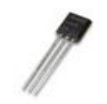

d)

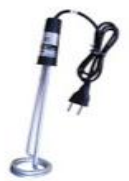

g)

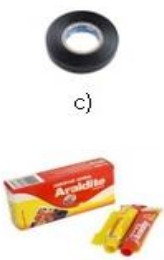

e)

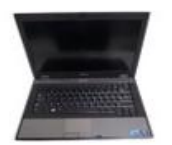

h)
Fig. 5 Materias used for the temperature control: (a) arduino; (b) 5V relay; (c) tape insulation; (d) temperature sensor LM35; (e) epoxy glue; (f) cables connectors; (g) electrical resistance and (h) computer.

Uno, a resistance for auxiliary heating of the water, a temperature sensor LM35, a relay of $5 \mathrm{~V}$, epoxy glue, cables, electrical tape and a computer to carry out the programming. The materials are shown in Fig. 5.

After gathering all the necessary materials, the programming for the temperature control was made. All programming was developed in the Arduino software. It was programmed so that every three seconds a new temperature reading was made and shown on the display. The water temperature control was made with a variation of $278.15 \mathrm{~K}$, for example, in a control between 318.15 and $323.15 \mathrm{~K}$ when programming is started, the temperature sensor checks the water temperature, if it is less than $318.15 \mathrm{~K}$, the relay is activated and the electrical resistance (which is immersed in the water) is switched on. After three seconds, the sensor relays the temperature, if it is above $323.15 \mathrm{~K}$, the resistance is turned off.

When it is necessary to analyze a new temperature range, the minimum and maximum temperature values are edited.

\subsection{Collection and Processing of Data}

The temperature control system and solar desalinator were coupled and the result is shown in Fig. 6.

The electrical resistance was placed inside the aluminum vessel with sea water and 10 temperature control ranges were chosen, they are shown in Table 1.

For each temperature range, 3 analyses per day were performed over a period of 2 days, for example: for the temperature range $\mathrm{T} 1$, three analyses per day were performed, one in the period from 9:00 a.m. to 11:00 a.m., another from 12:00 to 2:00 p.m. and the last from 3:00 p.m. to 5:00 p.m. for two days.

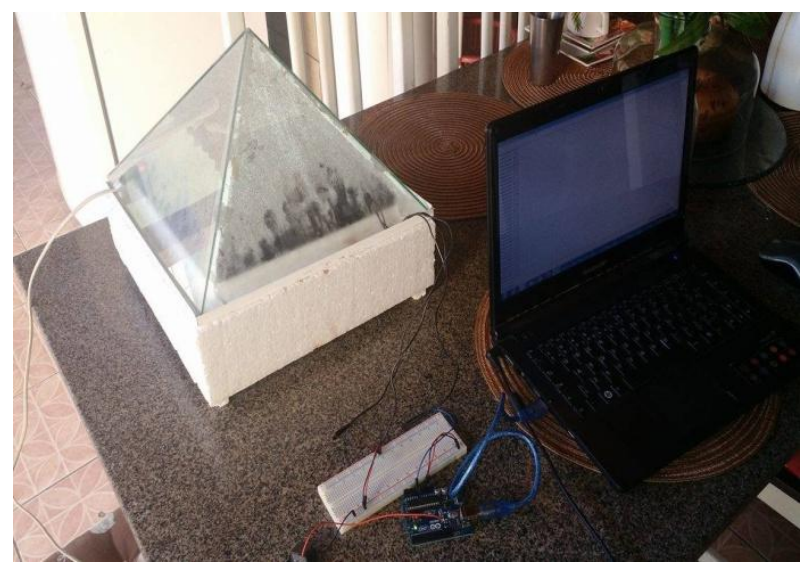

Fig. 6 Desalinator in conjunction with the temperature control system.

Table 1 Temperature range.

\begin{tabular}{ll}
\hline Temperature & Range $(\mathrm{K})$ \\
\hline T1 & $318.15-323.15$ \\
T2 & $323.15-328.15$ \\
T3 & $328.15-333.15$ \\
T4 & $333.15-338.15$ \\
T5 & $338.15-343.15$ \\
T6 & $343.15-348.15$ \\
T7 & $348.15-353.15$ \\
T8 & $353.15-358.15$ \\
T9 & $358.15-363,15$ \\
T10 & $363.15-368.15$ \\
\hline
\end{tabular}


Data collection occurred over a period of 20 days. It is important to note that, on rainy or cloudy days, the samples were canceled to avoid the influence of lower temperature and higher humidity in the desalinator production [16-17].

As the data collected for the same conditions were close, a simple mean was used to represent the results of each temperature range.

\section{Experimental Results}

From the data collected and treated, the graph contained in Fig. 7 was constructed. It is possible to verify a direct relationship between the temperature and the production of the solar desalinator.

For the temperature range of $\mathrm{T} 1$, a production of 17 $\mathrm{mL}$ per hour of desalinator operation was verified for an area of 90,000 $\mathrm{mm}^{2}$ of treated water as shown in Fig. 3 . Doubling this temperature range, the production of the desalinator increased more than sixfold, reaching production of $110 \mathrm{~mL}$ per hour.

From this graph it is possible to build another, this time relating the temperature to the production in liters per hour per square meter, as shown in Fig. 8 .

For a range temperature $\mathrm{T} 10$ it is possible to produce more than one liter of desalinated water per hour.

Using the average between each temperature range it becomes possible to obtain the graph of Fig. 9. It shows the production of the equipment in a continuous dotted line and the second degree polynomial that generates the trend line in dotted lines.

From the graph of Fig. 9, Eq. (1) is generated to predict the production according to the water temperature in the desalinator vessel.

$$
P=0,0000007 t^{4}-0,0002 t^{3}+0,0201 t^{2}-0,9126 t+15,159 \text { (1) }
$$

Where $P$ is the production in liters per hour per square meter and $t$ is the temperature in Kelvin. Therefore, it is verified that the higher the temperature of the fluid, the greater the solar desalinator production.

According to the results obtained, it is noted that the use of other equipment associated with the solar desalinator is totally justified, such as: the solar

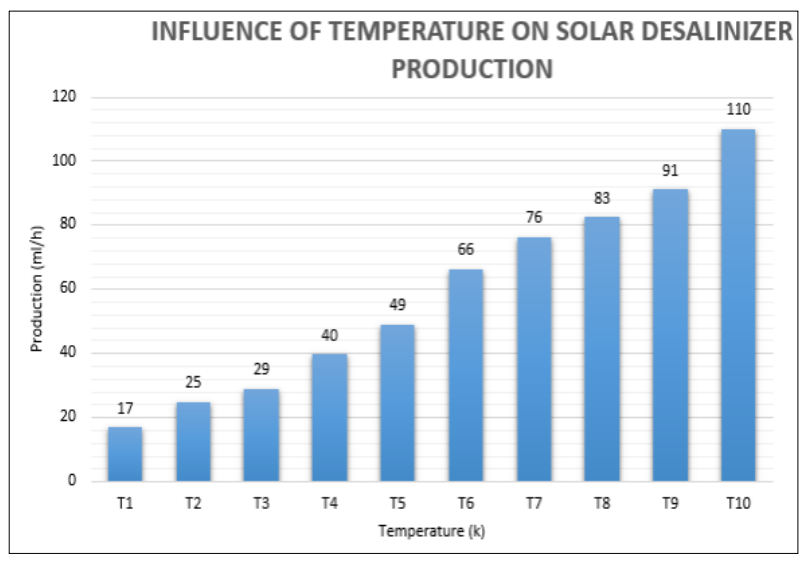

Fig. 7 Influence of the water temperature on solar desalinator production, production in $\mathrm{ml}$ per hour.

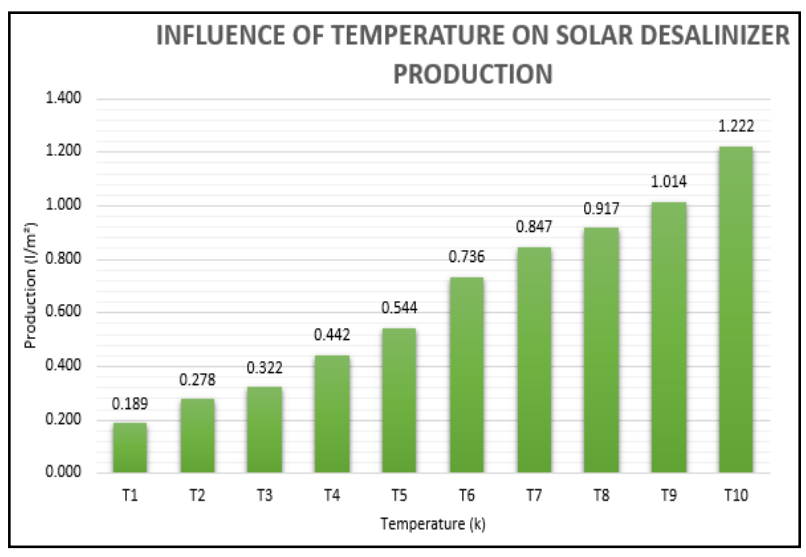

Fig. 8 Influence of the water temperature on the production of solar desalinator, production in liters per hour per square meter.

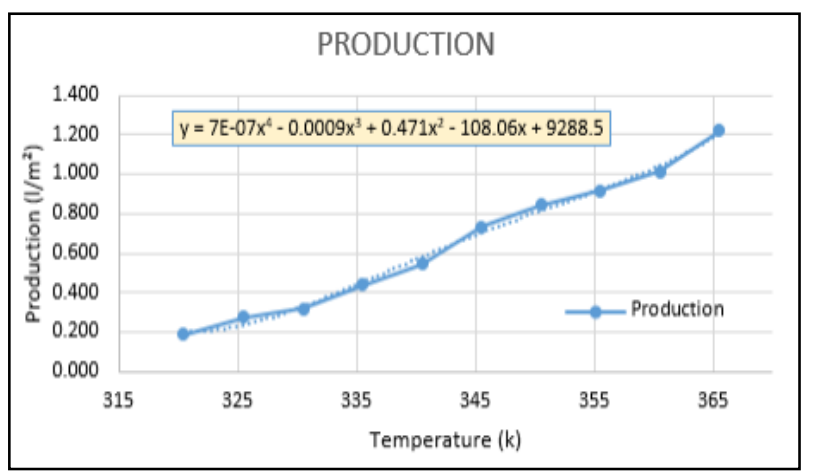

Fig. 9 Production as function of the temperature and the trend line polynomial.

collector with absorber surface in PVC liner sheets developed by Reis [18] was able to heat the water to a temperature above $325.15 \mathrm{~K}$; the alternative low cost solar heater proposed by Costa [19] was able to heat the water up to $55^{\circ} \mathrm{C}$; vacuum tube solar heater that 
Xie [20] studied through a conceptual and experimental analysis, reached a temperature of up to $358.15 \mathrm{~K}$ in the water.

In fact, the higher the temperature reached by the auxiliary heating system, the better the desalinator production.

\section{Conclusions}

From the results obtained:

- It is possible to build a solar desalinator with materials found in any commercial center of any city;

- Arduino is a tool that enables the automation of systems and with this allows to obtain results more faithful to reality;

- The relationship between temperature and production of a compact solar desalinator has been proven and quantified.

\section{References}

[1] Schiermeier, Q. 2014. "Water Risk as World Warms." Nature 505: 10-1.

[2] Aldabó, R. 2002. Energia Solar. São Paulo: Artliber Editora. p. 240.

[3] Shiva Gorijan, B. G. 2015. "Solar Desalination: A Sustainable Solution to Water Crisis in Iran." Renewable and Sustainable Energy Reviews 48: 571-84.

[4] Lima, R. S. 2012. "Sistema de destilação solar com pré-aquecimento em concentrador cilindro parabolic." Dissertação (mestrado em engenharia mecânica), Universidade Federal do Rio Grande do Norte, Natal. p.71.

[5] Abujazar, M. S. S. 2016. "The Effects of Design Parameters on Productivity Performance of a Solar Still for Seawater Desalination: A Review." Desalination 385: 178-93.

[6] Al-Hinai, H., et al. 2002. "Effect of Climatic, Design and Operational Parameters on the Yield of a Simple Solar Still." Energy Conversion and Management 140: 1639-50.

[7] Frota, A. B., and Schiffer, S. R. 2001. Manual do conforto térmico. 5th ed., São Paulo: Studio Nobel. p. 244.
[8] Pereira, E. B., et al. 2006. Atlas Brasileiro de Energia Solar. 1st ed., São José dos Campos: Swera. p. 60.

[9] Sharon, H., and Reddy, K. S. 2015. "A Review of Solar Energy Driven Desalination Technologies." Renewable and Sustainable Energy Reviews 41: 1080-118.

[10] Omara, Z. M., and Eltawil, M. A. 2013. "Hybrid of Solar Dish Concentrator, New Boiler and Simple Solar Collector for Brackish Water Desalination.” Desalination 326: 62-8.

[11] Al-Garni, A. Z. 2014. "Effect of External Reflectors on the Productivity of Solar Still during Winter." Journal of Energy Engineering 140.

[12] Cooper, P. I. 1973. "The Maximum Efficiency of Single-Effect Solar Stills.” Solar Energy 15: 201-17.

[13] Deronzier, J. C., Lauro, F., and Ployart, R. 1981. "Solar Desalination: Prototype 'Pithon' a Special Solar Multiple-Effect Distiller.” Dessalination 39: 117-23.

[14] Chendo, M. A. C., and Egariewe, S. U. 1991. "Effects of Pebbles and Wick on the Performance of a Shallow Basin Solar Still." In Proceedings of the Biennial Congress of the International Solar Energy Society, 2264-9.

[15] Candelas, F. A., et al. 2015. "Experiences on Using Arduino for Laboratory Experiments of Automatic Control and Robotics." IFAC-PapersOnLine 48: 105-10.

[16] Durkaieswaran, P., and Murugavel, K. K. 2015. "Various Special Designs of Single Basin Passive Solar Still-A Review." Renewable and Sustainable Energy Reviews 49: 1048-60.

[17] Kumar, P. V., et al. 2015. "Solar Stills System Design: A Review." Renewable and Sustainable Energy Reviews 51: 153-81.

[18] Reis, E. P. 2009. "Análise do desempenho térmico de um sistema de aquecimento solar utilizando coletor com superfície absorvedora em chapas de forro de PVC." Dissertação (mestrado em engenharia mecânica), Universidade Federal do Rio Grande do Norte, Natal. p 84.

[19] Costa, R. N. A. 2007. "Viabilidade térmica, econômica e de materiais de um sistema solar de aquecimento de água a baixo custo para fins residenciais." Dissertação (mestrado em engenharia mecânica), Universidade Federal do Rio Grande do Norte, Natal. p. 78.

[20] Xie, G., et al. 2016. "Conceptual Design and Experimental Investigation Involving a Modular Desalination System Composed of Arrayed Tubular Solar Stills." Applied Energy 179: 972-84. 